\title{
Kadın Sağlığında Mindfulness (Bilinçli Farkındalık) ve Kullanim Alanları
}

\author{
Gamze BİLGíç゙, Özlem CAN GÜRKAN**
}

$\ddot{\mathbf{O} z}$

Bilinçli farkındalık, yargılayıcı olmayan bir şekilde anda olma ve kabul edilebilme yeteneğini geliştiren bir tür meditasyon olup, psikolojik bir müdahaledir ve fiziksel ve psikolojik sağlığa etkilerini inceleyen çalışmaların sayısı gün geçtikçe artmaktadır. Kadın sağlığı, anne rahminden yaşlılığa kadar ele alınmalıdır. Bu dönemlerin her birinde bir takım fiziksel, psikolojik, spiritüel ve sosyal sorunlar yaşanabilmektedir. Kadının yaşadı̆̆ı bu dönemlere yönelik başvurulan alternatif bir terapi yöntemi olarak bilinçli farkındalık müdahalelerin kullanımı günden güne artmaktadır. Hemşirelerin kadın sağlığını sürdürme ve yaşanılan hastalık durumlarında iyileştirici rolü yadsınamaz derecede önemlidir. Bilinçli farkındalık müdahaleleri hemşirelerin gerekli eğitimleri aldıktan sonra hastalarına uygulayabileceği etkin bir yöntem olarak karşımıza çıkmaktadır. Bu derlemede, bilinçli farkındalık kavramını açıklamak, kadın sağlığındaki kullanım alanlarını incelemek ve bilinçli farkındalıkla ilgili çalışmaların kanıt düzeylerini değerlendirmek amaçlanmıştır.

Anahtar Kelimeler: Bilinçli farkındalık, kadın sağlığı, doğum.

\footnotetext{
Derleme Makale (Review Article)

Geliş / Received: 14.07.2020 \& Kabul / Accepted: 30.04.2021

DOI: https://doi.org/10.38079/igusabder.760381

${ }^{*}$ Uzm. Hemşire, SBய̈ Erenköy Ruh ve Sinir Hastalıkları Eğitim ve Araştırma Hastanesi, İstanbul, Türkiye, E-posta: gamzetasdelenbilgic@gmail.com ORCID https://orcid.org/oooo0002-2742-1089

${ }^{* *}$ Dr. Öğr. Üyesi, Marmara Üniversitesi, Sağllk Bilimleri Fakültesi, Hemşirelik Bölümü, Doğum ve Kadın Hastalıkları Hemşireliği Anabilim Dalı, İstanbul, Türkiye, E-posta: ozlemcan@marmara.edu.tr ORCID https://orcid.org/o000-0002-5608-6208
} 


\title{
Mindfulness and its Use in Women's Health
}

\begin{abstract}
Mindfulness is a psychological intervention, a type of meditation that enhances the ability to be present and to be accepted in a non-judgmental way, and the number of studies examining its effects on physical and psychological health is increasing day by day. Women's health has to be handled from mother's womb to ageing, and may experience some physical, psychological, spiritual and social problems in each of these periods. Women's health should be addressed from the womb to old age. In each of these periods, some physical, psychological, spiritual and social problems can be experienced. The healing role of nurses in maintaining women's health and the disease experienced is undeniably important. Mindfulness interventions emerge as an effective method that nurses can apply to their patients after receiving the necessary training. In this review, it is aimed to explain the concept of mindfulness, examine the usage areas in women's health and evaluate the evidence levels of conscious awareness studies.
\end{abstract}

Keywords: Mindfulness, women's health, birth.

\section{Giriş}

Bilinçli farkındalık eski bir Budist yaklaşımı olup en basit tanımı bilinçli yaşama sanatıdır. Bireyin dikkatini şu anda olmakta ve olanlara yargılayıcı olmadan, kabullenici

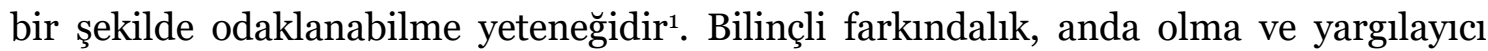
olmayan bir şekilde kabul edilebilme yeteneğini geliştiren bir tür meditasyon olarak tanımlanmıştır².

Bilinçli farkındalık müdahaleleri psikolojik bir müdahaledir. Farkındalık uygulamaları, stresi azaltması, zihni sakinleştirmesi, ağrıyı azaltması, uyku kalitesini artırması, kronik bel ve sırt ağrılarını azaltması nedeniyle psikolojik iyilik hali ile ilişkilidir³. İnsanın psikolojik iyi oluşunu sağlamak adına olumsuz deneyimlere maruz kaldığında içsel duyguları tanıma ve kabul etme ile hafifletmeyi hedefler ${ }^{45}$. Psikolojik iyilik hali; zihinsel ve fiziksel sağlı̆̆ı etkileyen olumlu duygularla bağlantılı olup ${ }^{6}$ ruhsal, duygusal ve zihinsel iyi oluş olarak tanımlanmaktadır7. Bireylerin pozitif psikolojik iyilik haline sahip olduklarında, hayatlarında zihinsel ve duygusal olarak en iyi durumda bulunmadığı zamanlar olsa bile, problemleriyle baş edebildiği ifade edilmiştir ${ }^{6}$. 
Bilinçli farkındalık temelli müdahalelerin kullanımı artmakta ve bunun klinik yararları ile ilgili giderek büyüyen bir literatür oluşmaktadır ${ }^{1,5,8-10}$. Bilinçli farkındalık kullanımının erişkinler, öğrenciler, kanser hastaları, depresyon, sağlık çalışanları gibi birçok farklı örneklem üzerinde etkili olduğu bildirilmiştir ${ }^{4,6,9,11}$. Bilinçli farkındalık müdahalelerinin kadın sağlığına olumlu etkileri ve maliyet açısından uygun olması sebebiyle son yıllarda giderek artan bir konu haline gelmiştir ${ }^{12-14}$.

$\mathrm{Bu}$ derlemede, bilinçli farkındalık kavramını açıklamak, kadın sağlığındaki kullanım alanlarını incelemek ve bilinçli farkındalıkla ilgili çalışmaların kanıt düzeylerini değerlendirmek amaçlanmıştır. Çalışmaların kanıt düzeyleri Joanna Briggs Enstitüsü kanıt düzeyi sınıflamasına (2013) göre verilmiştir (Tablo 1). Derlemenin hazırlık sürecinde, PubMed / Medline, CINAHL Plus, PsycInfo, Cochrane Database of Systematic Reviews ve ULAKBİM, Google Akademik veri tabanlarından "Mindfulness" "Women health" "Birth" "Bilinçli farkındalık" "Kadın sağlı̆̆l" "Doğum" anahtar kelimeleriyle arama yapılmış ve elde edilen makaleler değerlendirilmiştir.

Tablo 1. Joanna Briggs Enstitüsü Kanıt Düzeyi Sınıflaması (Joanna Briggs, 2013)

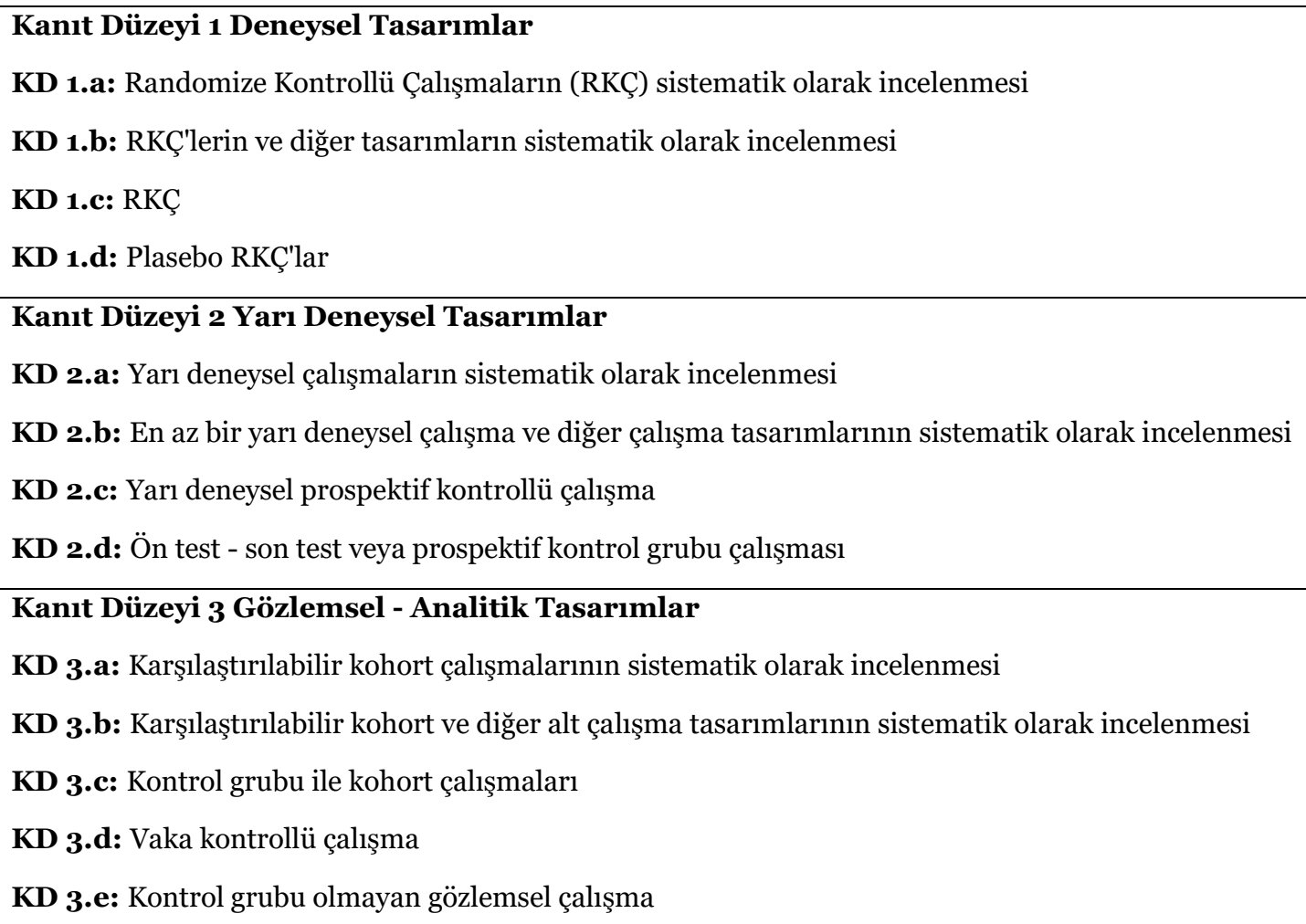




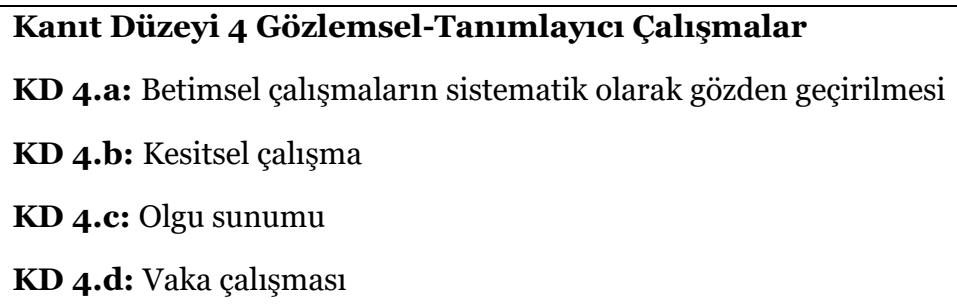

\section{Bilinçli Farkındalık Kavramı}

Bilinçli farkındalık kullanımı git gide yaygınlaşmakta olup, kavram olarak hala birçok farklı biçimlerde ifade edilmektedir ${ }^{10,15}$. Bilinçli farkındalık kişinin hislerini, düşüncelerini, bedenini, bilincini ve çevresini olduğu gibi yargılamadan kabul etmesini tanımlayan bir süreci ifade eder9,10. Yüksek konsantrasyonu, şimdiki anın farkındalığını aktif bir şekilde sürdürmeyi, dışarıdan ve içsel, hem hoş hem de hoş olmayan deneyimleri izlemeyi ve şimdiki an hakkında tam bir kabul, açıklık, yargılamama ve merakı içerir³. 1972 ylında Kabat-Zinn tarafından stres azaltmak için geliştirilen bilinçli farkındalık müdahaleleri; ilk başlarda yalnızca kronik ağrısı olan hastaları tedavi etmek için kullanılmış sonraları ise fiziksel veya zihinsel ağrı şikâyeti olan hastalara stres, zor durumlar ve bunların oluşturduğu hislerle baş etme becerisi kazandırmaya yönelik bir müdahaleye dönüşmüştür ${ }^{16}$.

Jon Kabat-Zinn, bilinçli farkındalık uygulamasının temel tutumlarını şu şekilde açıklamaktadır:

- Yargılamama: Kişinin görüş, inanç, zevk ve hoşlanmadıklarını bir kenara bırakıp yaşadıkları deneyimi gözlemleme.

- Sabır: Her şeyin olması gereken zamanda olacağını kabul etme.

- Acemi zihni: Çevresindeki her şeyi ilk kez görmeye istekli olma.

- Güven: Kişinin kendine ve temel bilgeliğine güvenmesi. 
- Hırslanmamak: Kişi hiçbir şey yapmasa da farkındalık konusunda deneyim sahibi olacağını kabul etmeli.

- Kabul: Her şeyi görmek istediğimiz gibi değil olduğu gibi görmek.

- Oluruna bırakmak: Kişi her ne yaşanıyorsa, deneyimliyorsa; bunlara sıkı sıkıya tutunmaktan ziyade, olanları gerçekleştiğinin farkına vararak geçip gitmelerine izin vermek ${ }^{2}$.

Bilinçli farkındalık "otomatik pilota” aldığımız günlük rutinlerimizin farkına vararak ve anda olarak devam etmemizi sağlar. Farkındalık hem beceri hem de bir uygulama gerektirir ve dikkatli kalma becerisini doğurur. Kişi hayatın iniş ve çıkışlarında dikkatli kalma becerisi ne kadar güçlü ise, o kadar kolay baş edebilecektir9. Bilinçli farkındalığın artması ile kişi sevgi, şefkat ve affetme duygularını besleyerek öz-anlayış ve öz şefkat seviyelerinde bir artış sağlar ve böylece kişi olumsuz duygu durumlarından daha az etkilenir. Bilinçli farkındalık halinde kişi rahat, mutlu, şefkatli, hazır ve uyanıktır Bilinçli farkındalık müdahaleleri kişilerin psikolojik iyi oluşlarını iyileştirmenin yanı sıra fiziksel olarak da kan basıncını ve kan şekerini düzenlediği, kalp atım hızını yavaşlattığı, yorgunluk ve aktivite düzeylerini iyileştirdiği çalışmalarla kanıtlanmıştır ${ }^{8,9,14}$. Kişinin bilinçli farkındalığının düzeyi; Özyeşil ve ark, 2011 yılında geliştirdiği bilinçli farkındalık ölçeği ile ölçülebilir. Bu ölçek kişinin anlık deneyimlerin farkında olma ve deneyimlere karşı dikkatli olma becerisine dair bireysel farklılıkları ölçmektedir . Farkındalık becerilerini geliştirmek ve iyileştirmek için farkındalık temelli programlara katılmak önemlidir.

Bilinçli farkındalık uygulayıcılarının sahip olması gereken belirli yeterlilikleri vardır. Bunlar her bir müdahale oturumunun kapsamı, ilerleme hızı ve organizasyonunu sağlayabilmek; kişilerarası ilişki becerilerine sahip olmak; tanımlanmış farkındalık uygulamalarını ustaca yönlendirebilmek; ders temalarını interaktif bir şekilde sorgulayabilmek; grup diyalogu ve didaktik öğretme sağlamak; grup öğretme / öğrenme ortamının etkin tutulması ve tüm bunlar için özel olarak uyarlanmış eğitim şartlarının sağlanması olarak sayılabiliri ${ }^{16}$. Ulusal ve uluslararası kuruluş ve kurulların belirlediği uygulama esasları ve etik ilkeler dâhilinde oluşturulmuş yetkin kişilerce verilen eğitimleri tamamladıktan sonra kişiler uygulayıcı olabilmektedir. Ülkemizde bu 
kuruluşlar tarafından eğitici eğitmeni olan kişi ve kurumlar mevcut olup, düzenlenen programlara katılarak uygulayıcı olunabilmektedir.

\section{Kadın Sağlığında Bilinçli Farkındalık Müdahalelerinin Kanıt Temelli Kullanımı}

Kadın; yaşam döngüsü çerçevesinde anne rahminden başlayarak, çocukluk, ergenlik, erişkinlik ve yaşlılık gibi farklı dönemlerden geçmekte ve bu dönemlerin her birinde bir takım fiziksel, ruhsal ve sosyal değişiklikler yaşamaktadır. Yaşanılan bu değişiklikler, kadınların üretkenliklerini ve yaşam kalitelerini olumsuz yönde etkileyebilmektedir. Hemşirelerin kadının yaşadığı sorunları önlemek için koruyucu bakım verme, oluştuğu durumlarda tanılama, uygun tedavi edici müdahaleyi yapma ve gerekli olduğunda sevk etme gibi sorumlulukları vardır ${ }^{17}$. Bu bağlamda bilinçli farkındalık temelli müdahale programları kadın sağlığını iyileştirmek adına hemşireler tarafından uygulanabilecek kanıt temelli bir uygulama olarak karşımıza çıkmaktadır. Bilinçli farkındalık temelli müdahale programları ve bunların etkinliğini değerlendirmek amacıyla yapılan çalışmalar, müdahalenin stres ve anksiyeteyi azaltarak iyi oluşu olumlu etkilediğini, aynı zamanda fiziksel sağlı̆̆ı da iyileştirdiğini göstermektediri1, 8-10,14.

\section{İnfertilite ve Bilinçli Farkındalık}

Infertilite tedavisi kadınlar için hem fiziksel hem de psikolojik açıdan yorucu ve yıpratıcı bir süreç olabilmektedir. İnfertilite tedavisi sürecinde; tedavinin başarısı, cinsel istek/isteksizlik, orgazm problemleri kadının psikososyal sağlı̆̆ından etkilenmektedir ${ }^{18,19}$. Bu dönemde psikolojik iyi oluşu desteklemek amacıyla yapılan müdahaleler önem kazanmaktadır. Jing ve ark.'ın ${ }^{13}$ Çin'deki bir hastaneye başvuran; bilinçli farkındalığın infertil kadınlarda cinsel yaşam kalitesine etkisini incelemek için yaptıkları kesitsel tipteki çalışmada; kadınların farkındalıkları arttıkça cinsel yaşamlarındaki özgüven ve otonominin arttığı ve daha kaliteli bir cinsel yaşama sahip oldukları belirlenmiştir (Kanıt Düzeyi 4b). Fard ve ark.'nın ${ }^{12}$ kontrollü deneysel çalışmalarında; infertilite hastalarına 8 seanslık stres terapi eğitimi bilinçli farkındalık temelli müdahale uygulanmış ve infertilite hastalarının psikolojik iyi oluşlarının kontrol grubuna göre istatistiksel olarak anlamlı düzeyde arttığı belirlenmiştir (Kanıt Düzeyi 2d). Li ve ark.' $^{20}$ bilinçli farkındalık müdahalesinin IVF tedavisi gören infertil çiftlerdeki etkinliğini inceledikleri çalışmada; müdahalenin psikolojik iyi oluşu arttırmasının yanı 
sıra, gebelik oranlarını da arttırdığını bulmuşlardır (Kanıt düzeyi 2c). Bilinçli farkındalık müdahaleleri infertilite tedavisi esnasında yaşanan stres ve anksiyeteyi azaltmakta, tedavinin başarı oranlarını arttırmakta ve hiçbir yan etkisi olmadığı için güvenle kullanılabilmektedir.

\section{Perinatal Dönem, Doğum ve Bilinçli Farkındalık}

Perinatal dönemde gebenin yaşadığı stres, anksiyete ve depresyon gibi durumlar maternal, ve fetal fizyolojiyi etkileyerek ciddi psikolojik problemlere zemin hazırlayabilmektedir. Günümüzde, perinatal dönemde anksiyete ve depresyonu tedavi etmek amacıyla kullanılan medikal tedavinin gebelik sürecini ve fetüsü sağlığını olumsuz etkileyeceğinden endişe edildiği için medikal olmayan alternatif müdahalelerin önemi artmaktadır $^{21}$. Veringa ve ark.'r ${ }^{22}$ şiddetli düzeyde doğum korkusu yaşayan 128 gebe ve onların eşlerine 6 ay boyunca bilinçli farkındalık temelli danışmanlık yapmışlar ve bu danışmanlığın doğum korkusu, gebelikle ilişkili stres ve depresyon düzeyine etkisini araştırmışlardır. Araştırma sonucunda; doğum korkusunun müdahale öncesine göre istatistiksel olarak azaldığını ve psikolojik iyi oluşun müdahale öncesine göre istatistiksel olarak arttığını tespit etmişlerdir (Kanıt düzeyi 2d). Yine aynı şekilde Hulsboch ve ark.'nın²3 gebelik stresini azaltmaya yönelik online bilinçli farkındalık müdahale programının gebelikteki stresi ve anksiyeteyi anlamlı düzeyde azalttığını bulmuşlardır (Kanıt düzeyi 2c). Pan ve ark.'nın²4 bilinçli farkındalık ve doğum öz-yeterliliğinin artırılması için doğum öncesi stres ve depresyonun azaltılmasına yönelik sekiz haftalık farkındalık tabanlı doğum ve ebeveynlik programının etkinliğini araştırmak amacıyla yaptıkları çalışma sonucunda; kadınların stres ve depresyon düzeyleri azalmış; farkındalık ve doğum öz yeterlilik düzeyleri anlamlı derecede artmıştır (Kanıt Düzeyi 2c).

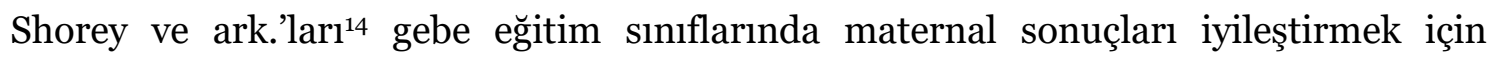
uygulanan bilinçli farkındalık müdahalelerinin, hem fizyolojik hem de psikolojik etkilerini değerlendiren çalışmaları sistematik olarak incelemişler ve gebe eğitim sınıflarında hemşireler tarafından uygulanan bilinçli farkındalık müdahalesinin maternal iyi oluşa olumlu etkileri olduğunu tespit etmişlerdir. Bu iyilik halinin yalnızca psikolojik değil, fiziksel olarak da kan basıncını ve kan şekerini düzenlediği, kalp atım hızını yavaşlattığı, yorgunluk ve aktivite düzeylerini iyileştirdiği sonuçlarını bildirmişlerdir (Kanıt Düzeyi 1c ). 


\section{Jinekolojik Kanserler ve Bilinçli Farkındalık}

Kadınlar yaşamının herhangi bir döneminde kanser tanısı alabilir ve tedavi sürecine maruz kalabilirler. Dünya Kanser İzleme (GLOBACAN) 2018 verilerine göre; dünya genelinde kadınlarda en sık görülen kanser türleri \%24.2 ile meme kanseri ve \% 10.7 ile serviks kanserdir25. Kanser tanısı almış kadınlar tedavi süreci ve semptomların sıklığı ile baş etmek zorunda kaldıkları için stres ve anksiyete yaşayabilirler, hayat kaliteleri, cinsel yaşamları ve mental sağlıkları olumsuz etkilenebilir ${ }^{26}$. Psikolojik iyi oluşu artıran müdahalelerden biri olan bilinçli farkındalık temelli müdahaleler kanser tanısı almış kadınlarda psikolojik iyi oluşu artırmak için bir yöntem olarak kullanılabilir ${ }^{27,28}$. Stafford

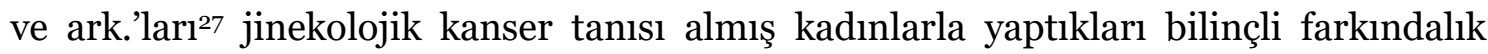
temelli müdahale programı sonrasında, kadınların psikolojik iyi oluşlarının ve bilinçli farkındalıklarının arttığını ve stres düzeylerinin azaldığını bulmuşlardır (Kanıt düzeyi 2d). Sarenmalm ve ark.' ${ }^{28}$ bilinçli farkındalığın meme kanseri tanısı almış kadınlarda psikolojik ve biyolojik etkilerini incelemek amacıyla yaptıkları çalışmalarında; basit rastgele yöntemle seçilen 166 kadın üç gruba ayrılmıştır. İlk gruba 8 hafta süren bilinçli farkındalık temelli stres azaltma müdahalesi uygulanmıştır. İkinci gruba bilinçli farkındalık ile stres azaltma hakkında eğitim verilmiş ve kendi kendilerine uygulamaları istenmiş ve düzenli aralıklarla kontrolleri yapılmıştır. Üçüncü gruba ise bilinçli farkındalıkla ilgili hiçbir uygulama ve bilgilendirme yapılmamıştır. Yapılan müdahalelerin psikolojik etkileri depresyon ve anksiyete değerlendirme ölçekleriyle, biyolojik etkileri ise sitokin, lenfosit ve enzimlerin bakıldığı kan örnekleriyle değerlendirilmiştir. Gruplar arası yapılan kıyaslama sonucu bilinçli farkındalık müdahalesi en etkili sonuçları birinci grupta daha sonra ikinci grupta vermiştir. Bilinçli farkındalık müdahalesinin kanser tanısı almış kadınlarda anksiyete ve depresyonu azalmasının yanı sıra sitokin, lenfosit ve enzim sayılarını artırarak vücutlarının enfeksiyonlara daha iyi cevap verebilecek kapasiteye gelmiştir. Sonuç olarak bilinçli farkındalık temelli müdahalelerin hem psikolojik hem de biyolojik olarak meme kanserli kadınlarda efektif bir müdahale olarak kullanılabilir (Kanıt Düzeyi 2c).

\section{Menopoz ve Bilinçli Farkındalık}

Menopoz, bir kadının, üreme yaşamının sonuna ulaştığında menstrüasyon döngüsünün durmasıdır. Menopoz, kadınlar tarafından üremenin bitip yaşlanmanın başladığı dönem 
olarak kabul edildiğinden kadın yaşamında büyük önem taşımaktadır²9. Menopozdan 26 yll önceki dönem olarak kabul edilen perimenopozal dönemde, vazomotor semptomlar, baş ağrısı, uykusuzluk, yorgunluk ve ruhsal rahatsızlıklar gibi birçok yakınma ortaya çıkmaya başlamaktadır. Bu yakınmaları yaşamak ve baş etmek kadınlar için stres kaynağı olmaktadır ${ }^{30}$. Sood ve ark.'ının ${ }^{31}$ menopoz sürecindeki kadınların bilinçli farkındalık ve stres düzeyleri arasındaki ilişkiyi incelemek için 1744 kadınla yaptıkları kohort çalışmalarında; bilinçli farkındalık puanları yüksek olan kadınların daha düşük düzeyde stres ve daha az menopoz semptomu yaşadıkları bildirilmiştir (Kanıt düzeyi 3e). Menopozal döneme geçiş aşamasında uygulanan beden-zihin temelli müdahale programlarının menopoz semptomlarına etkisini araştıran makalelerin sistematik derlemesinde; 4 ülkede 919 kadına uygulanan bilinçli farkındalık, yoga, meditasyon müdahalelerinin, sıcak basmaları, duygudurum dalgalanmaları ve ağrı şikayetlerini azalttığı, uyku kalitesini arttırdığı sonucuna varılmıştır² (Kanıt Düzeyi 1c) .

\section{Sonuç ve Öneriler}

Bilinçli farkındalık temelli müdahalelerin kullanımı gün geçtikçe artmakta ve bunun klinik yararları çalışmalarca kanıtlanmaktadır. Güncel veriler ışığında bilinçli farkındalık temelli müdahalelerin kadınların yaşamlarının her dönemlerindeki stresörlerle mücadele etmek için kullanabilecekleri etkin bir yöntem olduğunu ortaya koyan kanıt düzeyi yüksek çalışmalara rastlanmıştır. Elde edilen bu çalışmalar ışığında kadınlarda yöntemin yalnızca stresi azaltmak amacıyla değil fizyolojik yararları olan etkili bir yöntem olarak kullanılabileceği söylenebilir. Hemşirelere yapılan temel düzey farkındalık eğitimlerinin artırılması, bilinçli farkındalık temelli müdahalelerin bakıma dâhil edilmesi, gerekli işbirliklerinin sağlanarak kadınların yaşam dönemlerine özel sorunlara yönelik müdahale programların geliştirilmesi ve bunların sonuçlarının değerlendirilmesi önerilir.

\section{KAYNAKLAR}

1. Özyeşil Z. Öz-Anlayış ve Bilinçli Farkındalık. Ankara: Maya Akademi Yayınevi; 2011. 
2. Kabat - Zinn, J. Mindfulness- based interventions in context: past, present, and future. Clinical Psychology: Science And Practice. 2003;10(2):144-156.

3. Huynh T, Torquati JC. Examining connection to nature and mindfulness at promoting psychological well-being. Journal of Environmental Psychology. 2019;(66):101370.

4. Monteiro LM, Musten RF, Compson J. Traditional and contemporary mindfulness: Finding the middle path in the tangle of concerns. Mindfulness. 2015;6(1):1-13.

5. Hayes SC, Strosahl KD, Wilson KG. Acceptance And Commitment Therapy: The Process And Practice Of Mindful Change. 2nd ed.New York: The Guilford Press; 2012.

6. Fagbenro DA, Ehigie OB, Folasade AO. Influence of stages of pregnancy on the psychological well-being of pregnant women in Ibadan, Nigeria. International Journal of Caring Science. 2018;11(2):719-724.

7. Rowold J. Effects of spiritual well-being on subsequent happiness, psychological well-being, and stress. Journal of Religon and Health. 2011;50:950-963.

8. Bishop SR. Mindfulness: a proposed operational definition. Clinical Psychology: Science and Practice. 2004;11(3):230-241. doi: 10.1093/clipsy/bpho77.

9. Hofmann SG, Gómez AF. Mindfulness-based interventions for anxiety and depression. Psychiatric Clinics of North America. 2018;40(4):739-749.

10. Purser RE, Milillo J. Mindfulness revisited: a buddhist-based conceptualization. Journal of Management Inquiry. 2015;24(1):3-24. doi: 10.1177/1056492614532315.

11. Schell LK, Monsef I, Wöckel A, Skoetz N. Mindfulness-based stress reduction for women diagnosed with breast cancer. Cochrane Database of Systematic Reviews. 2019;3(3): CDo11518.

12. Fard TR, Kalantarkousheh M, Faramarzi M. Effect of mindfulness-based cognitive infertility stress therapy on psychological well-being of women with infertility. Middle East Fertility Society Journal. 2018;23:476-481. 
13. Jing L, Hong L, Ling L. Mindfulness and fertility quality of life in Chinese women with infertility: assessing the mediating roles of acceptance, autonomy and selfregulation. Journal of Reproductive \& Infant Psychology . 2019;37(5):455-467.

14. Shorey S, Ang L, Yin C. A. Systematic mixed-studies review on mindfulness-based childbirth education programs and maternal outcomes. Nursing Outlook. 2019;67(6):696-706.

15. Van Gordon W, Shonin E, Griffiths MD, Singh NN. There is only one mindfulness: Why science and Buddhism need to work together. Mindfulness. 2015;6(1):49-56. doi: 10.1007/s12671-014-0379-y.

16. Crane RS, Brewer J, Feldman C, et al. What defines mindfulness-based programs? The warp and the weft. Psychol Med. 2017;47:990-9.

17. Koyun A, Taşkın L, Terzioğlu F. Yaşam dönemlerine göre kadın sağlığı ve ruhsal işlevler: hemşirelik yaklaşımlarının değerlendirilmesi. Psikiyatride Guncel Yaklasimlar/Current Approaches to Psychiatry. 2011;3(1):67-99.

18. Potur Coşkuner D, Satılmış İG, Doğan Merih Y, Gün Kakaşçı Ç, Demirci N, Ersoy M. Does infertility affect the sexual function and sexual quality of life of women? a case control study. International Journal Of Sexual Health. 2020;32(1):22-32. https://doi.org/10.1080/19317611.2019.1692983.

19. Erdem K, Ejder Apay S. A sectional study: the relationship between perceived social support and depression in turkish infertile women. Royan Institute International Journal of Fertility and Sterility. 2014;8(3):303-314.

20. Li J, Long L, Liu Y, He W, Li M. Effects of a mindfulness-based intervention on fertility quality of life and pregnancy rates among women subjected to first in vitro fertilization treatment. Behav Res Therapy. 2016;77:96-104.

21. Ashford MT, Olander EK, Ayers S. Computer- or web-based interventions for perinatal mental health: A systematic review. Journal of Affective Disorders. 2016;197:134-146.

22. Veringa IK, Bruin EI, Bardacke N, et al. I've changed my mind', Mindfulnessbased childbirth and parenting (MBCP) for pregnant women with a high level of 
fear of childbirth and their partners: study protocol of the quasi-experimental controlled trial. BMC Psychiatry. 2016;16:377.

23. Hulsbosch LP, Nyklíček I, Potharst ES, et al. Online mindfulness-based intervention for women with pregnancy distress: design of a randomized controlled trial. BMC Pregnancy Childbirth. 2020;20:159. doi:10.1186/s12884-020-2843-o.

24. Pan WL, Gau ML, Lee TY, Jou HJ, Liu CY, Wen TK. Mindfulness-based programme on the psychological health of pregnant women. Women and Birth. 2019;2(1):e102-e109.

25. Globacan. https://gco.iarc.fr/today/data/factsheets/populations/900-world-factsheets.pdf. Erişim tarihi 16 Mayıs 2020.

26. Mehnert A. Koch U. Psychological comorbidity and health-related quality of life and its association with awareness, utilization, and need for psychosocial support in a cancer register-based sample of long-term breast cancer survivors. Journal of Psychosomatic Research. 2008;64(4):383-391.

27. Stafford L, Foley E, Judd F, Gibson P, Kiropoulos L, Couper J. Mindfulness-based cognitive group therapy for women with breast and gynecologic cancer: a pilot study to determine effectiveness and feasibility. Supportive Care in Cancer. 2013;21:3009-3019.

28. Sarenmalm EK, Martensson LB, Andersson BA, Karlsson P, Bergh I. Mindfulness and its efficacy for psychological and biological responses in women with breast cancer. Cancer Medicine. 2017;6(5):1108-1122. doi: 10.1002/cam4.1052.

29. Bhore NR. Coping strategies in menopause women: A comprehensive review. Innovational Journal of Nursing and Healthcare. 2015;1(4):244-253.

30. Bozkurt Demirel Ö, Sevil Ü. Menopoz ve cinsel yaşam. Celal Bayar Üniversitesi Sağlık Bilimleri Enstitüsü Dergisi. 2016;3(4):497-503.

31. Sood R, Kuhle CL, Kapoor E, et al. Association of mindfulness and stress with menopausal symptoms in midlife women. Journal of Climacteric. 2019;22(4):377382. 
32. Woods NF, Mitchell ES, Schnall JG, et al. Effects of mind-body therapies on symptom clusters during the menopausal transition. Journal of Climacteric. 2014;17:10-22. 